\title{
Composition of gall bladder stones associated with octreotide: response to oral ursodeoxycholic acid
}

S H Hussaini, S P Pereira, G M Murphy, C Kennedy, J A H Wass, G M Besser, R H Dowling octreotide treatment induces gall bladder stones in $13-60 \%$ of patients after 3 to 51 months' treatment. ${ }^{12}$

Gall stones are conventionally classified as: (i) cholesterol rich stones (arbitrarily $>70 \%$ cholesterol by weight: they may also contain variable amounts of calcium salts and bile pigments) and (ii) non-cholesterol stones - that is, brown pigment and black pigment stones. Anecdotal reports suggest that most gall stones found during octreotide treatment are radiolucent, ${ }^{34}$ presumed cholesterol rich, and dissolvable with oral bile acid therapy. ${ }^{3-5}$ There have been no systematic studies of the composition and dissolvability of gall stones found during octreotide treatment - essential information for studies of their pathogenesis, treatment, and prevention. We therefore studied stone composition in 14 octreotide treated acromegalic patients with gall stones using direct and indirect methods, including, in a subgroup of nine, stone dissolvability during oral bile acid therapy.

\section{Patients and methods}

Fourteen acromegalic patients (eight men), with a mean age of 52 years (range 25 to 66) were studied. They had been treated with a mean dose of $300 \mu \mathrm{g}$ octreotide/day (range 150-600) for a mean duration of 19 months (range 3 to 36 ) before their gall stones were diagnosed by ultrasonography. At the time the stones were detected, none of the patients had symptoms related to gall stones. In one, a 43 year old woman, octreotide had been stopped for nine months after she had been treated for a total of three years. Three patients were shown to be free of stones by ultrasound before octreotide treatment began. They were found to have developed gall stones three, 12 , and 15 months after starting octreotide, and their stones were therefore classified as octreotide induced. In the remaining 11 , no imaging studies of the gall bladder had been carried out before octreotide treatment to exclude preexisting stones: they were, therefore, described as octreotide associated gall stones.

GALL STONE COMPOSITION

Gall stones, retrieved at cholecystectomy, were available for direct chemical analysis in two of 14 patients: in the remaining 12 , indirect methods of predicting stone composition were used: (i) localised computed tomography of the gall bladder and (ii) analysis of gall bladder bile.
Octreotide, a long acting analogue of somatostatin, suppresses both growth hormone and insulin like growth factor 1 secretion and is used to treat acromegaly. However, long term 
Direct analysis of stone composition

One acromegalic patient underwent elective cholecystectomy because of recurrent biliary colic. In the second, a sailor, the gall bladder was removed 'prophylactically' to prevent the remote chance ${ }^{6}$ of gall stone related complications while he was at sea.

The macroscopic appearance of the outer and cut surfaces of the stones (Fig 1) was noted and the stones were dried, weighed, and ground to a powder. The resultant powder was then alkalinised with $1 \%$ sodium bicarbonate and its cholesterol was extracted using chloroform:methanol (2:1 volume). The chloroform phase containing the cholesterol was separated from the methanol phase and evaporated to dryness in a rotary evaporator. The residue was then resolubilised in isopropanol, its cholesterol content was assayed enzymatically, ${ }^{7}$ and the results were expressed as a percentage of dry stone weight.

\section{Indirect analysis of stone composition}

Localised computed tomography of the gall bladder $(n=12)$. We, ${ }^{8}$ and others, ${ }^{9-11}$ have shown that the maximum gall stone attenuation score, measured in Hounsfield units (HU), provides an indirect measure of stone composition and dissolvability. In our experience, a computed tomography score of less than $100 \mathrm{HU}$ predicts cholesterol rich and therefore potentially dissolvable stones. ${ }^{12}$ For this reason, localised computed tomography of the gall bladder was performed in 12 acromegalic patients with octreotide associated gall stones.

Sampling and analysis of gall bladder bile. In six of the 12 patients who underwent localised computed tomography of the upper abdomen, bile was obtained by ultrasound guided, fine needle puncture of the gall bladder. ${ }^{13} 14$ Of the remaining six, gall bladder puncture was attempted but failed in two. Gall bladder puncture was not attempted in two further patients as they had a blocked cystic duct (non-opacification of the gall bladder at oral cholecystography). Two patients refused consent.

\section{Detection of cholesterol microcrystals}

Cholesterol microcrystals were identified by polarised light microscopy from their classical, notched rhomboid shape and the fact that they were negatively bi-refringent. The presence of cholesterol microcrystals in gall bladder bile is a sensitive and specific predictor of cholesterol rich stones. ${ }^{15-19}$

\section{Measurement of cholesterol saturation indices}

Total biliary bile acids, phospholipids, and cholesterol were determined by standard enzymatic assays. ${ }^{72021}$ The cholesterol saturation indices were then derived using a polynomial equation. ${ }^{22}$ Saturation indices $>1.0$ indicate bile that is supersaturated with cholesterol - a prerequisite for the formation of both cholesterol microcrystals ${ }^{23}$ and cholesterol rich gall stones.

\section{Measurement of cholesterol microcrystal}

nucleation/appearance time

Immediately after obtaining the gall bladder bile, aliquots were centrifuged at $100000 \mathrm{~g}$ for two hours. This resulted in a precipitate phase consisting of cellular debris and solid cholesterol crystals, a supernatant phase of liquid crystals, and an 'isotropic' middle phase. Aliquots of this isotropic phase were isolated, incubated at $37^{\circ} \mathrm{C}$, and examined daily by polarised light microscopy, for up to 21 days. ${ }^{24}$ The time taken for cholesterol microcrystals to appear was defined as the nucleation time (or more accurately, the time for crystal formation, growth, and detection), measured in days. Gall bladder bile from patients with cholesterol rich gall stones nucleates in less than 10 days. ${ }^{24-26}$

\section{DISSOLVABILITY OF GALL STONES WITH ORAL BILE ACID THERAPY}

\section{Patient selection}

Patients with conventional gall stone disease (unrelated to acromegaly or octreotide treatment) are usually selected for oral dissolution therapy with ursodeoxycholic \pm chenodeoxycholic acids (UDCA \pm CDCA) if they: (i) complain of specific gall stone related symptoms and (ii) have potentially dissolvable, cholesterol rich and calcium free stones (as judged by oral cholecystography and computed tomography) measuring $<15-20 \mathrm{~mm}$ maximum diameter, in a 'functioning' gall bladder (see below).

In this series, none of the 12 patients with octreotide associated stones complained of gall stone related symptoms. Moreover, four of the 12 had calcified stones (as judged by a maximum stone attenuation score of $>100 \mathrm{HU}$ ). Nonetheless, we decided to treat all 12 with oral UDCA to determine whether the octreotide associated gall stones were dissolvable, as an indirect measure of gall stone composition, since cholesterol rich gall stones are potentially dissolvable with oral bile acid therapy. ${ }^{2}$

To assess cystic duct patency, a meal stimulated ultrasound scan of the gall bladder was performed in all 12 patients who did not undergo cholecystectomy. This was done at least eight hours after the last subcutaneous dose of octreotide - by which time the inhibitory effects of octreotide on gall bladder contraction have worn off. ${ }^{27}$ An arbitrary reduction in the fasting gall bladder volume of $>20 \%$, 30 minutes after eating a $200 \mathrm{~g}$ chocolate bar, was taken as evidence of a patent cystic duct. If the reduction was $<20 \%$, oral cholecystography was performed and if the gall bladder failed to opacify, the procedure was repeated with a double dose of contrast.

\section{Gall stone characteristics}

All 12 acromegalic patients had more than two gall stones (mean (SEM) $7 \cdot 4(0 \cdot 9)$ ), and eight of the 12 had more than eight, with a mean 
Individual results of direct and indirect studies of gall stone composition in 14 acromegalic patients with octreotide induced/associated stones

\begin{tabular}{|c|c|c|c|c|c|c|c|}
\hline \multirow[b]{3}{*}{ Patient } & \multicolumn{2}{|c|}{ Gall stone composition } & \multicolumn{3}{|c|}{ Gall bladder bile analysis } & \multirow{2}{*}{\multicolumn{2}{|c|}{$U D C A$ treatment }} \\
\hline & \multirow{2}{*}{$\begin{array}{l}\% \text { Cholesterol } \\
\text { (by weight) }\end{array}$} & \multirow{2}{*}{$\begin{array}{l}\text { CT attenuation } \\
\text { score }(H U)\end{array}$} & \multirow{2}{*}{$\begin{array}{l}\text { Cholesterol } \\
\text { crystals }\end{array}$} & \multirow[b]{2}{*}{ CSI } & \multirow[b]{2}{*}{$N T$} & & \\
\hline & & & & & & Started & Response \\
\hline $1^{\star}$ & 71 & - & - & - & - & No & - \\
\hline $2^{\star}$ & 87 & - & - & - & - & No & - \\
\hline 3 & - & 42 & - & - & - & No & - \\
\hline 4 & - & 106 & - & - & - & No & - \\
\hline 5 & - & 217 & No & 1.01 & 4 & Yest & $t$ \\
\hline 6 & - & 23 & Yes & $1 \cdot 29$ & 1 & Yes & None \\
\hline 7 & - & 65 & Yes & 1.53 & 1 & Yes & None \\
\hline 8 & - & 40 & Yes & 1.90 & 1 & Yes & Partial GSD \\
\hline 9 & - & 490 & No & 1.09 & 4 & Yes & Partial GSD \\
\hline $10^{\star}$ & - & 63 & Yes & $1 \cdot 10$ & 1 & Yes & Complete GSD \\
\hline 11 & - & 50 & - & - & - & Yes & Complete GSD \\
\hline 12 & - & 66 & - & - & - & Yes & Partial GSD \\
\hline 13 & - & 123 & - & - & - & Yes & None \\
\hline 14 & - & 51 & - & - & - & Yes & None \\
\hline
\end{tabular}

UDCA = ursodeoxycholic acid; $C T=$ computed tomography; $C S I=$ cholesterol saturation index $\mathrm{NT}=$ nucleation time; $\mathrm{GSD}=$ gall stone dissolution; *octreotide induced gall stones; flost to follow up.

(SEM) maximum diameter of $8 \cdot 1(0.9) \mathrm{mm}$ (range 2-14). Two patients had a blocked cystic duct and were therefore considered unsuitable for oral UDCA treatment.

\section{Treatment and follow up}

The patients were assessed clinically for gall stone related symptoms. A full blood count, fasting serum lipids, alkaline phosphatase, alanine transaminase, gamma glutamyl transferase, bilirubin, albumin, and total protein were measured. The 10 acromegalic patients with a patent cystic duct were then started on oral UDCA treatment, in a dose of 10 $\mathrm{mg} / \mathrm{kg} /$ day, taken at bedtime. With the exception of the 43 year old woman in whom octreotide treatment had been stopped, all patients continued on this treatment while taking UDCA.

The patients were followed up every three months, at which time they were assessed clinically, their liver function tests and fasting serum lipids concentrations were measured, and ultrasound of the gall bladder was carried out. Although 10 patients with ocreotide associated gall stones and a patent cystic duct began UDCA treatment, one was lost to follow up (patient no 5 in the table). The gall stone

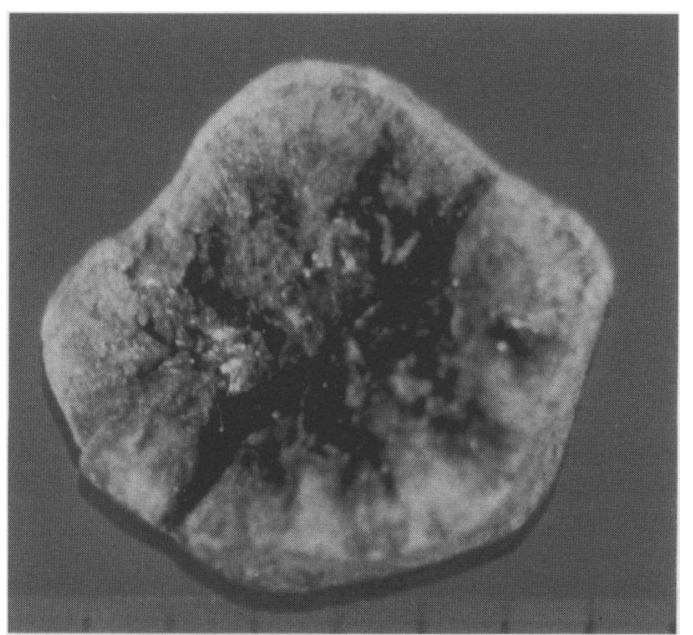

Figure 1: Gall stone from one patient with octreotide induced gall stones. The stones were multiple smooth faceted stones. The cut surface shows a pigmented centre with a radiating lattice composed of crystalline cholesterol. dissolution response to oral therapy was therefore assessed in only nine patients. Moreover, one of these (no 12) emigrated after six months of treatment, although by that time his response to UDCA had already been assessed at the three and six month follow up visits.

If, after six months of UDCA therapy, there was no reduction in either the maximum stone diameter or number, or both, an oral cholecystogram was performed to exclude blockage of the cystic duct. In four of the five patients treated with oral bile acids for more than 12 months who had no ultrasound evidence of gall stone dissolution, a localised computed tomogram of the gall bladder was repeated to exclude acquired gall stone calcification. Furthermore, in four of these five patients a second oral cholecystogram was carried out after 16-20 months of UDCA treatment. In the fifth, who became intolerant or oral contrast media, a ${ }^{99} \mathrm{~m}$ Tc-HIDA $\left({ }^{99} \mathrm{~m}_{\text {tech- }}\right.$ netium-labelled diethyl hydroxyimino diacetic acid) radionucleotide scan was performed to assess cystic duct patency.

Partial gall stone dissolution was defined as a reduction in stone number or diameter of at least $50 \%$. Complete gall stone dissolution was accepted only after two consecutive ultrasound scans of the gall bladder, one month apart during continued oral UDCA treatment, confirmed the absence of stones.

UDCA treatment was stopped for any one of the following three reasons: (i) when complete gall stone dissolution was confirmed, (ii) if patients were found to have developed a blocked cystic duct; or (iii) if stones had not dissolved completely after 24 months' therapy.

\section{ETHICAL CONSIDERATIONS}

The use of ultrasound guided, fine needle puncture of the gall bladder was approved by the Research Ethics Committee of St Bartholomew's Hospital and by the Ethics Committee of Guy's Hospital. All patients gave their written informed consent.

\section{Results}

The results for stone composition and the response to oral bile acid therapy are given in the Table.

\section{STONE COMPOSITION}

\section{Direct analysis}

Both of the patients who underwent cholecystectomy had multiple, smooth, faceted gall stones. The cut surface of both sets of stones showed a pigmented centre with a surrounding lattice of radiating 'spokes' of cholesterol crystals (Fig 1). Direct chemical analysis of the stones showed that they contained $71 \%$ and $87 \%$ cholesterol by weight, respectively.

\section{Indirect analysis}

Localised computed tomography. The maximum computed tomography attenuation scores of 


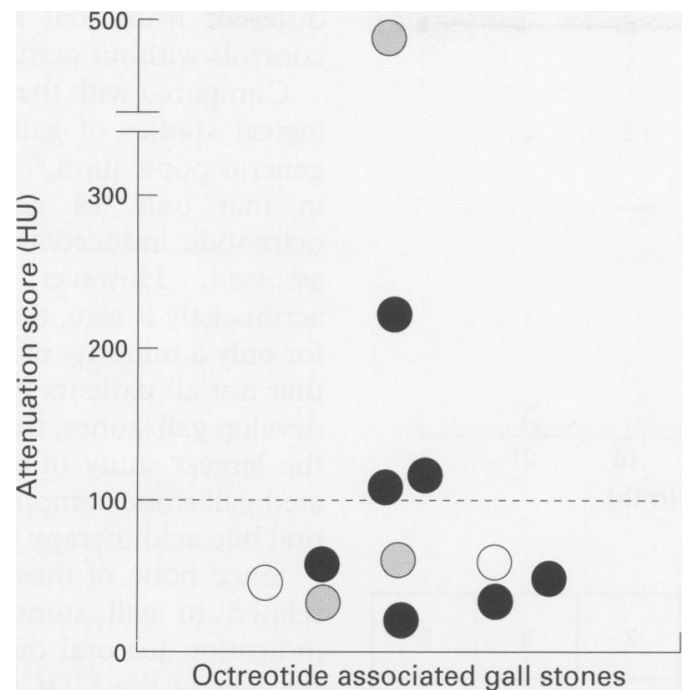

Figure 2: The maximum gall stone computed tomographic attenuation score, measured in Hounsfield units (HU), in 12 acromegalic patients with octreotide associated gall stones. The broken line at $100 \mathrm{HU}$ represents the cut off value below which stones are predicted to be cholesterol rich and potentially dissolvable. Those stones which did not dissolve with UDCA therapy are represented by the filled circles, those which partially dissolved are represented by the hatched circles and those which completely dissolved are represented by the open circles.

the gall stones from the 12 acromegalic patients are shown in Figure 2. Eight had stones with scores of $<100 \mathrm{HU}$ (range 23-66), while the remaining four had scores ranging from 106 to $490 \mathrm{HU}$.

Analysis of gall bladder bile. Cholesterol microcrystals were seen in the bile from four (nos 6, 7, 8, and 10) of the six acromegalic patients who underwent percutaneous gall bladder puncture. In all six patients, however, the bile was supersaturated with cholesterol with a mean cholesterol (SEM) saturation index of $1.19(0.08)(1.01-1.53)$.

In the four patients in whom biliary cholesterol microcrystals were seen, the nucleation time was invariably short (one day) and the maximum computed tomography attenuation scores were all $<100 \mathrm{HU}(23-64)$. In contrast, in the two in whom cholesterol microcrystals were not seen (nos 5 and 9), the nucleation

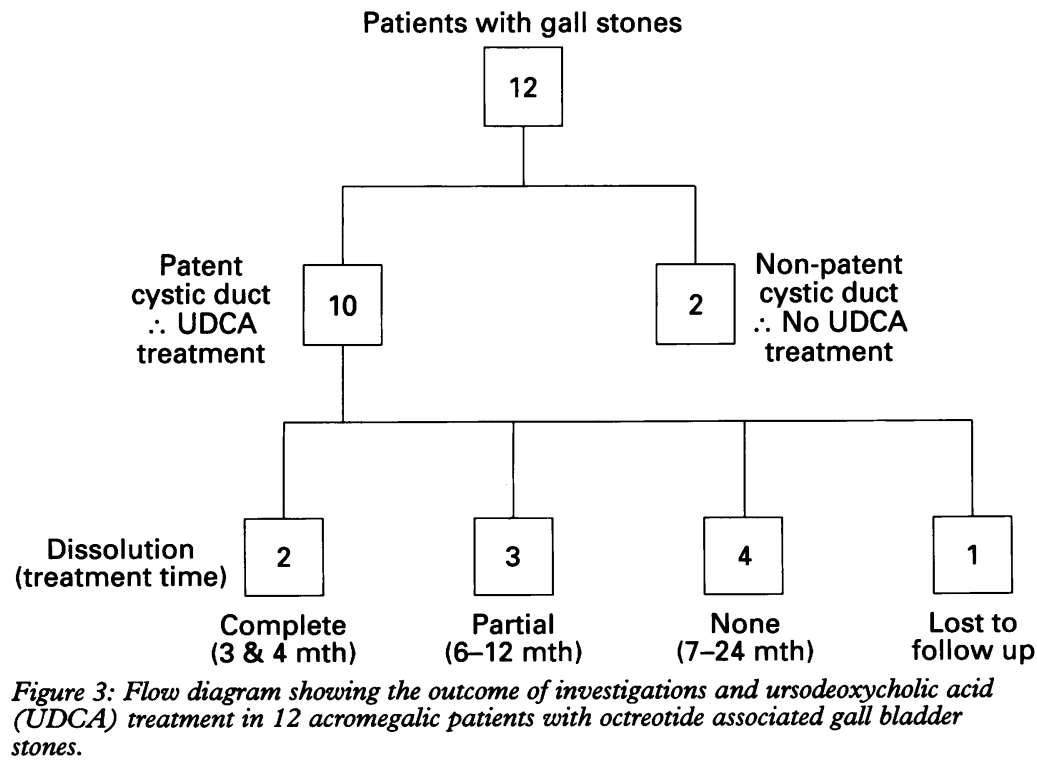

time was four days in both and the gall stones had maximum attenuation scores of 217 and $490 \mathrm{HU}$.

DISSOLVABILITY OF GALL STONES WITH ORAL BILE ACID THERAPY

The overall outcome of UDCA treatment in the 12 acromegalic patients with octreotide associated gall stones who were considered for oral bile acids, is summarised in Figure 3. The gall stone dissolution response (partial and complete), as calculated by actuarial or life table analysis, is shown in Figure 4.

As the results in Figure 3 show, complete gall stone dissolution was seen in two (nos 10 and 11 ) of the nine patients $(22 \cdot 2 \%)$, after three and four months UDCA therapy respectively. One of these (no 11) had stopped octreotide nine months before starting UDCA treatment. In the second, the induced gall stones dissolved with oral UDCA despite continued octreotide therapy.

Partial stone dissolution occurred in three patients (33.3\%) after 6 to 12 months UDCA. As noted above (see 'Treatment and follow up' in the Methods section), one of these (no 12) was lost to follow up after six months. A second (no 8), who had complained of biliary colic some nine months after starting UDCA, was found to have developed a blocked cystic duct at 21 months, while the third (no 9) had calcified stones before UDCA treatment began (computed tomography score $490 \mathrm{HU}$ ).

In the remaining four patients $(44.4 \%)$, there was no evidence of a stone dissolution response despite 7-24 months UDCA treatment. In fact, three of the four (nos 6, 7, and 14) had taken UDCA for 24 months, while the fourth (no 13) was found to have developed a non-opacifying gall bladder after seven months of bile acid treatment, as a result of which the UDCA treatment was withdrawn.

Life table analysis (Fig 4) shows that the cumulative percentages of patients with partial plus complete stone dissolution were 44.4 $(16.6) \%$ at six months' treatment and 58.3 $(15.9) \%$ after one year, and subsequently, although the number at risk by that time was only three.

Thus, by 12 months, five of the nine patients treated with UDCA and followed up were left with no, or incomplete, gall stone dissolution. The incomplete dissolution response did not seem to result from acquired gall stone calcification since repeat computed tomograms of the gall bladder after one year of UDCA treatment (nos 6, 8, 9, and 14) showed no increase in the maximum stone attenuation scores: the fifth patient (no 7) did not return for a repeat scan. Furthermore, with the exception of the patient who developed a blocked cystic duct (no 8), none of the other four patients who failed to respond completely developed a 'nonfunctioning' gall bladder.

None of the patients reported any adverse effects of UDCA treatment, and the results of their fasting serum lipid measurements and liver function tests remained normal and unchanged throughout. 


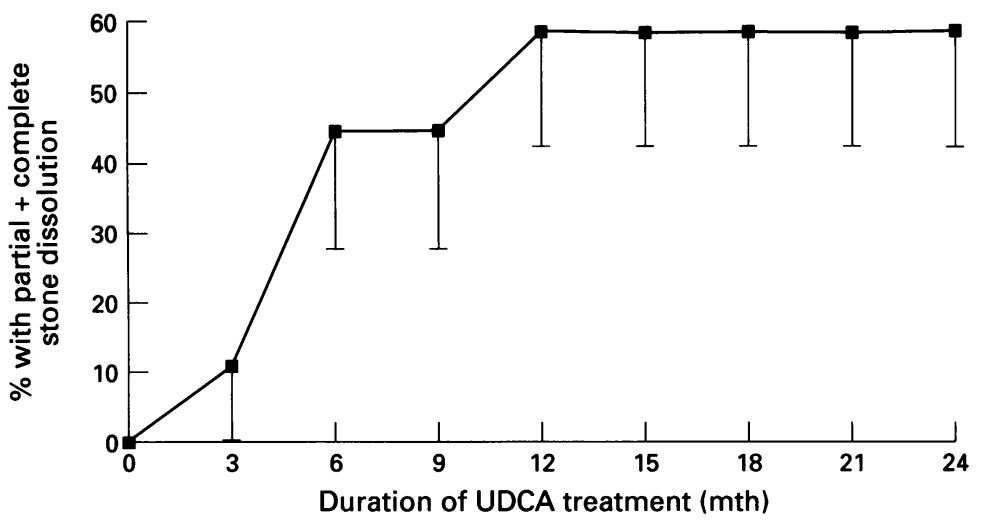

\begin{tabular}{|l|c|c|c|c|c|c|c|c|}
\hline $\begin{array}{l}\text { No at } \\
\text { risk }\end{array}$ & 9 & 8 & 4 & 4 & 3 & 3 & 3 & 3 \\
\hline $\begin{array}{l}\text { No with } \\
\text { P+C GSD }\end{array}$ & 1 & 3 & 0 & 1 & 0 & 0 & 0 & 0 \\
\hline
\end{tabular}

Figure 4: Actuarial or life table analysis showing the partial plus complete gall stone dissolution response (means (SEM)). The numbers of patients at risk and the number with partial (P) or complete (C) gall stone dissolution (GSD) at each time period, are shown above. different from that in age and sex matched controls without acromegaly. ${ }^{30}$

Compared with the results of large epidemiological studies of gall stone prevalence in the general population, ${ }^{29} 3233$ this study is limited in that only 14 acromegalic patients with octreotide induced/associated gall stones were assessed. However, given the facts that acromegaly is rare, that octreotide is prescribed for only a minority of acromegalic patients, and that not all patients given long term octreotide develop gall stones, the present series represents the largest study of octreotide induced/associated gall stone composition and the response to oral bile acid therapy yet reported.

Since none of these patients had symptoms related to gall stones, there was no clinical indication for oral dissolution agents. Instead, the aim of the UDCA treatment in this study was to assess, in an investigative setting, the dissolvability of the octreotide associated gall stones. For that reason, in the Results section and in Figure 4, we have emphasised the combined partial plus complete gall stone dissolution response. In the context of clinically indicated oral bile acid treatment, however, the sole criterionfor success is a symptom free patient with complete gall stone dissolution. patient (no 8) complained of two episodes of right upper quadrant pain lasting more than three hours. None of the others complained of gall stone related symptoms.

\section{Discussion}

These results show that in most patients with octreotide induced/associated gall stones, the stones are small, multiple, and cholesterol rich. However, unlike earlier reports, ${ }^{34}$ the stones in one third of our patients were dense on computed tomography (attenuation scores of $>100 \mathrm{HU}$ ) suggesting that they contained more than $3 \%$ calcium by weight. ${ }^{28}$ Moreover, before UDCA treatment, $17 \%$ of the patients reported here had a blocked cystic duct - a figure comparable to that found in epidemiological screening studies of the general (nonacromegalic) population. ${ }^{29}$ Despite the suggestion that octreotide associated gall stones should dissolve with oral bile acids, ${ }^{3-5}$ we found that during UDCA treatment, only two patients $(22 \%)$ showed complete gall stone dissolution.

\section{STUDY DESIGN}

Only three of our 14 patients had octreotide induced, as opposed to octreotide associated, gall stones. In theory, therefore, some of the remaining 11 could have had stones which antedated the octreotide treatment. In practice, this seems unlikely since the prevalence of stones in octreotide treated acromegalic patients ${ }^{12}$ is much higher than that in their counterparts who are not treated with octreotide. 53031 Indeed, in the same cohort of acromegalic patients as that studied here, $50 \%$ of those treated with octreotide were found to have gall stones. This compares with a prevalence of only $15 \%$ in untreated acromegaly - a figure which is not significantly

\section{DIRECT CHEMICAL ANALYSIS OF OCTREOTIDE} INDUCED GALL STONES

Based on our arbitrary definition (see above), both sets of octreotide induced gall stones retrieved at cholecystectomy were cholesterol rich ( $>70 \%$ cholesterol by weight). Despite this, $13 \%$ and $29 \%$ respectively of these stones comprised material that was not cholesterol, and although we did not assay the stones for calcium or bilirubin, the macroscopic appearance of their cut surface showed a pigment rich centre. These appearances are common in conventional gall stone disease, where the nucleus consists of calcium bilirubinate and other calcium salts. ${ }^{34}$ Furthermore, four of the 12 acromegalic patients studied by localised computed tomography, had stones with attenuation scores of $>100 \mathrm{HU}$, suggesting that they were either non-cholesterol in type or contained more than $3 \%$ calcium salts. ${ }^{28}$

INDIRECT ASSESSMENT OF STONE COMPOSITION

\section{Attenuation scores}

In our experience ${ }^{10}$ and that of others, ${ }^{35}$ a computed tomography attenuation score $<100 \mathrm{HU}$ predicts cholesterol rich stones which dissolve well with oral bile acid therapy. Of the four acromegalics with stones shown to be dense by computed tomography, only one also had a pretreatment ultrasound (to exclude gall stones before octreotide treatment). Thus, it remains possible that those with the highest computed tomography scores had pre-existing stones. The other two patients with octreotide induced gall stones had not undergone computed tomography before cholecystectomy.

In this series, the prevalence of stones that looked dense on computed tomography is 
similar to that of radio-opaque stones $(\approx 30 \%)$ in spontaneous gall stone disease. ${ }^{29}$ There are no comparable data on the prevalence of 'CT-dense' stones in the general gall stone population but, based on previous observations, 89 one would expect this to be higher than $30 \%$.

\section{Bile composition}

All six bile samples studied were supersaturated with cholesterol. This observation is compatible with the suggestion that these octreotide associated stones were rich in cholesterol. The sensitivity and specificity of supersaturated bile as a predictor of cholesterol gall bladder stones, however, is low. $\mathrm{We}^{36}$ and others $^{24}$ have often found supersaturated bile in obese people without gall stone disease, and sometimes in acalculous control subjects. For this reason, the presence of cholesterol microcrystals in bile ${ }^{19}$ and the rapid nucleation of biliary cholesterol crystals ${ }^{24-26}$ are better predictors of cholesterol stones than supersaturated bile. Thus, in a study by Ros et al, ${ }^{19}$ the positive predictive value of biliary cholesterol crystals was $95 \%$ for cholesterol rich gall stones. Furthermore, the rapid nucleation of cholesterol crystals clearly distinguishes between those with cholesterol rich and those with non-cholesterol stones ${ }^{25} 26$ or stone free subjects. ${ }^{24}$ In our experience, non-acromegalic patients with cholesterol rich stones invariably have nucleation times of $<$ five days while stone free acromegalic patients have nucleation times of $>10$ days. ${ }^{37}$

Only four of the six acromegalic patients whose bile composition was studied had cholesterol microcrystals in fresh bile immediately after aspiration. However, all six bile samples nucleated in < four days, suggesting that the stones were indeed cholesterol rich. In the two remaining patients who initially had no cholesterol microcrystals, the nucleation time was longer (four days) than that in those with crystals (one day), although in both cases it was still abnormally fast. Furthermore, the stones in these two patients had maximum attenuation scores of $>100$ HU, suggesting that they were either noncholesterol or mixed in composition, with appreciable amounts of calcium. In the event, despite the fact that one of these patients had the highest recorded attenuation score (490 $\mathrm{HU}$ ), there was unequivocal evidence of partial gall stone dissolution with oral UDCA therapy, suggesting that at least some of the stone must have consisted of dissolvable cholesterol. The present observation that biliary cholesterol microcrystals may occur in the bile of octreotide treated patients confirms the findings of Buscail et al. ${ }^{4}$ They showed that there was an appreciable increase in the prevalence of biliary cholesterol crystals during octreotide treatment when compared with that beforehand.

RESPONSE TO ORAL DISSOLUTION THERAPY Complete or partial stone dissolution occurred in five of nine patients treated with UDCA in whom follow up was possible, which suggests that at least part of these stones was composed of cholesterol. The complete stone dissolution rate in this study is similar to that in 126 patients without acromegaly, but with radiolucent stones, treated with UDCA in another study from our unit. ${ }^{38}$

Failure to dissolve stones completely with oral bile acid therapy may be due to: (i) an inadequate dose of bile acids; (ii) an adequate dose but poor patient compliance in taking the prescribed medication; (iii) despite adequate doses and a compliant patient, failure of the oral bile acids desaturate bile (cholesterol saturation index $<1 \cdot 0$ ); (iv) the development, during treatment, of cystic duct blockage; (v) acquired stone calcification; and (vi) the presence of stones which, before treatment, were lucent by both conventional radiology and computed tomography, but were none the less non-cholesterol in type.

In the present study, all nine patients were given $10 \mathrm{mg}$ UDCA $/ \mathrm{kg} /$ day - the optimum dose for stone dissolution in patients of normal weight $^{39}$ - and claimed to have taken their oral UDCA regularly. Two patients developed a blocked cystic duct - a similar proportion to that seen in conventional stone disease during UDCA therapy. ${ }^{38}$ None developed stone calcification while taking UDCA, and since none of the four non-responders developed gall stone related symptoms, there was no indication for cholecystectomy, and therein the opportunity for gall stone retrieval and analysis. We can only speculate, therefore, about the possibility of computed tomography lucent (HU scores of 23,65 , and 51), but non-dissolvable, stones in three of these four patients whose cystic duct remained patent. Bile composition was not assessed during UDCA treatment in these three patients. Thus, inadequate desaturation of bile cannot be excluded as a possible cause for non-dissolution of stones.

In theory, resistance to UDCA treatment as a result of concurrent octreotide therapy is possible, since eight of the nine patients with acromegaly treated with UDCA continued to take octreotide. However, there are no data on the influence of octreotide on the efficacy of UDCA in desaturating bile and dissolving gall stones. Nonetheless, four of the five patients who showed partial or complete stone dissolution, continued concurrent octreotide treatment, which suggests that octreotide does not affect UDCA efficacy adversely.

\section{PREDICTORS OF STONE COMPOSITION}

Of the 12 patients whose gall stone composition was assessed indirectly, only two had all of the following criteria for cholesterol rich stones: (i) a maximum attenuation score of $<100 \mathrm{HU}$; (ii) partial or complete gall stone dissolution; (iii) the presence of biliary cholesterol microcrystals; and (iv) a rapid nucleation time of $<5$ days. However, small amounts of calcium contamination may result in attenuation scores $>100 \mathrm{HU}$ and oral dissolution therapy may fail for a variety of reasons other than the presence of 
non-cholesterol stones. Because of this, the best indirect criteria for predicting stone composition are the presence of biliary microcrystals and rapid nucleation time. Four of the six patients who underwent biliary analysis had both cholesterol microcrystals and rapid nucleation, thus predicting that at least $67 \%$ of stones associated with octreotide treatment are cholesterol rich.

We conclude that octreotide induced/associated gall stones are generally small, multiple, and cholesterol rich. Although inhibition of meal stimulated CCK release, leading to gall bladder stasis, ${ }^{2}$ has been implicated in stone formation, we have shown elsewhere ${ }^{37}$ that gall bladder bile from acromegalic patients with octreotide associated stones is also: (i) supersaturated with cholesterol; (ii) rich in vesicular cholesterol; (iii) has a high vesicular cholesterol: phospholipid molar ratio; and (iv) nucleates rapidly to form cholesterol microcrystals - important defects in the pathogenesis of 'conventional' cholesterol gall stones in patients who do not have agromegaly. Finally, in common with spontaneous gall stone disease, some of the acromegalic patients with octreotide associated gall stones have a blocked cystic duct or stones which are contaminated with calcium.

This paper was presented to the annual meeting of the American Gastroenterological Association, Boston Massachusetts, May 1993 and published in abstract form in Gastroenterology 1993; 104 (4): A365.

This work was supported, in part, by grants from the Special Trustees of Guy's Hospital and Sandoz Pharma Ltd.

We thank: Professor Pat Kendall Taylor and Dr Andy James for permission to analyse one set of gall stones from a patient with octreotide induced gall stones.

1 Ho KY, Weissberger AJ, Marbach P, Lazarus L. Therapeutic efficacy of the somatostatin analog SMS 201995 (octreotide) in acromegaly. Ann Intern Med 1990 112: $173-81$.

2 Dowling RH, Hussaini SH, Murphy GM, Besser GM, Wass JAH. Gallstones during octreotide therapy. Metabolism 1992; 41 (S2): 22-33.

3 Souquet JC, Girard I, Valette PJ, Chayvialle JA. Sandostatin and gallbladder lithiasis. In: Sandostatin 1991: state of the art. Proceeding of a conference held in Monte Carlo, art. Proceeding of a conference

4 Buscail LE, Puel-Bousquet C, Harris AG, Tauber JPJ, Escourrou JR, Delvaux MM, et al. Effets sur la lithogenès biliaire du traitement au long cours par octréotide (SMS 201-995) chéz des patients acromégales. Gastroenterol Clin Biol 1991; 15: 800-4.

5 Sassolas G, Harris AG, James-Deidier A and the French SMS 201-995 acromegaly study group. Long term effect of incremental doses of the somatostatin analog SMS 201995 in 58 acromegalic patients. $尹$ Clin Endocrinol Metab 1990; 71: 391-7.

6 Ransohoff DF, Gracie WA, Wolfenson LB, Neubauser D. Prophylactic cholecystectomy or expectant management for silent gallstones. A decision analysis to assess survival. Ann Intern Med 1983; 99: 199-204.

7 Roschlau P, Bernt E, Gruber W. Enzymatic determination of total cholesterol in serum. $Z$ Clin Biochem 1973; 12 403-8.

8 Rajagopal SU, Bills P, Keightley A, Dowling RH. Predictive value of computed tomography (CT) of the gallbladder in determining gallstone type. Gut 1988; 29: A1487.

9 Brakel K, Lamers JS, Nijs HGT, Terpstra OT, Steen G, Blijenberg BC. Predicting gallstone composition with CT: in

10 Janowitz P, Zöller A, Swobodnik W, Wechsler JG Schumacher KA, Ditschuneit $H$. Computed tomography evaluation of radiolucent gallstones in vivo. Gastrointest Radiol 1988; 151: 1123-8.

11 Hickmann MS, Schwesinger WH, Bova JD, Kurtin WE Computed tomographic analysis of gallstones. Arch Surg 1986, 121. 289-91.

12 Walters JRF, Hood KA, Gleeson D, Ellul JPM, Keightley A, Murphy GM, et al. Combination therapy with ora ursodeoxycholic acid and chenodeoxycholic acids: pretreatment computed tomography of the gall bladder improves
13 Swobodnik W, Hagert N, Janowitz P, Wenk H. Diagnostic fine needle puncture of the gallbladder with US guidance. Radiology 1991; 178: 755-8.

14 Hussaini SH, Kennedy C, Pereira SP, Wass JAH, Dowling RH. Ultrasound-guided percutaneous fine needle puncture of the gallbladder for studies of bile composition. $B r \mathcal{F}$ Radiol 1994 (in press).

15 Holzbach RT, Marsh M, Olszewski M, Holan K Cholesterol solubility in bile: evidence that supersaturated bile is frequent in healthy man. $\mathcal{f}$ Clin Invest 1973; 53: $1467-79$.

16 Carey MC, Small DM. The physical chemistry of cholesterol solubility in bile: relationship to gallstone formation and dissolution in man. 7 Clin Invest 1978; 61: 998-1026.

17 van der Linden W, Nakayama F. Occurrence of cholesterol crystals in human bile. Gut 1974; 15: 630-5.

18 Sedaghat A, Grundy SM. Cholesterol crystals and the formation of cholesterol gallstones. $N$ Engl F Med 1980 302: 1274-7.

19 Ros E, Navarro S, Fernandez I, Reixach M, Ribo JM, Rodes J. Utility of biliary microscopy for the prediction of the chemical composition of gallstones and the outcome of dissolution therapy with ursodeoxycholic acid. dissolution therapy with ur
Gastroenterology 1986; 91: 703-12.

20 Qureshi MY, Murphy GM, Dowling RH. The enzymatic determination of total phospholipids in bile and bile rich duodenal aspirates. Clin Chim Acta 1980; 105 407-10.

21 Talalay P. Enzymatic analysis of steroid hormones. Method Biochem Anal 1960; 8: 119-43.

22 Thomas PJ, Hofmann AF. A simple calculation of the lithogenic index of bile: expressing biliary lipid composition on rectangular co-ordinates. Gastroenterology 1972; 65: 698-700.

23 Admirand WH, Small DM. The physiochemical basis for the formation of cholesterol gallstones in man. $\mathcal{f}$ Clin the formation of choleste
Invest 1968; 47: 1043-52.

24 Holan KR, Holzbach RT, Hermann RE, Cooperman AM Claffey NJ. Nucleation time: a key factor in the pathogenesis of cholesterol gallstone disease. Gastroenterology 1979; 77: 611-7.

25 Janowitz P, Swobodnik W, Wechsler JG, Zöller A, Kuhn K Ditschuneit $\mathrm{H}$. A comparison of gall bladder bile and endoscopically obtained duodenal bile. Gut 1990; 31 1407-10.

26 Gollish SH, Burnstein MJ, Ilson RG, Petrunka CN, Strasberg SM. Nucleation of cholesterol monohydrate crystals from hepatic and gallbladder bile of patients with cholesterol gallstones. Gut 1983; 24: 836-44.

27 Stolk MFJ, van Erpecum KJ Koppeschar HPF, de Bruin WI, Jansen JBM, Lamers CBWH, et al. Postprandial gall bladder motility and hormone release during intermittent bladder motility and hormone release during intermittent and continuous subcutaneous oct

28 Rajagopal SU, Keightley A, Bills P, Walters JRF, Murphy GM, Dowling RH. The predictive value of pre-treatment CT scanning vs conventional radiology in determining composition, dissolvability and fragmentability of the gallbladder stones. $\mathcal{F}$ Hepatol 1989; 9: S211.

29 Anonymous. GREPCO: Radiological appearance of gallstones and its relationship with biliary symptoms and awareness of having gallstones. Dig Dis Sci 1987; 32: 349-53.

30 Catnach SM, Anderson JV, Fairclough PD, Trembath RC, Wilson PAJ, Parker E, et al. The effect of octreotide on gall stone prevalence and gall bladder motility in acromegaly. Gut 1993; 34: 270-3.

31 Singh S, Olliff J, O'Brien I, Langman MJ, Sheppard MC Stewart PM. Prevalence of gallstones in acromegalics untreated with somatostatin. European fournal of Gastroenterology and Hepatology 1993; 5: 541-2.

32 Barbara L, Sama C, Labate AMM, Taroni F, Rusticali AG Festi D, et al. A population study on the prevalence of gallstone disease: the Sirmione study. Hepatology 1987; 7 913-7.

33 The MICOL Group. Prevalence of gallstone disease in 18 Italian population samples: First results from the Micol study. In: Capocaccia L, Ricci G, Angelico F, et al, eds. Recent advances in the epidemiology and prevention of Recent advances in the epidemiology and prevention of gallstone disease. Dordrech

34 Sutor DJ, Wooley SE. A statistical survey of gallstone composition in eight countries. Gut 1971 ; 12 55-64.

35 Caroli A, Del Favero G, Di Mario F, Spigariol F, Scanlon $\mathrm{P}$, Meggiato T, et al. Computed tomography in predicting gallstone solubility: a prospective trial. Gut 1992; 33: 698-700.

36 Reuben A, Maton PN, Murphy GM, Dowling RH. Bile lipid secretion in obese and non-obese individuals with and without gallstones. Clin Sci 1985; 69: 71-9.

37 Hussaini SH, Murphy GM, Kennedy C Besser GM, Was JAH, Dowling RH. The role of bile composition and physical chemistry in the pathogenesis of octreotidephysical chemistry in the pathogenesis of octreotide-

38 Gleeson D, Ruppin DC, Saunders A, Murphy GM Dowling RH. Final outcome of ursodeoxycholic acid treatment in 126 patients with radiolucent gallstones $Q \mathcal{F M e d} 1990$; 76: 711-29.

39 Maton PN, Murphy GM, Dowling RH. Ursodeoxcholic acid treatment of gallstones. Dose response studie and a possible mechanism of action. Lancet 1977; ii 1297-301. 